\title{
Até onde vai a religião: um estudo do elemento religioso nos movimentos da Nova Era
}

\author{
How far religion goes: a study of the religious element in New Age \\ movements
}

Silas Guerriero *

\begin{abstract}
Resumo
Os estudos sobre os Novos Movimentos Religiosos geram questionamentos acerca da própria natureza da religião. Muitos desses movimentos podem ser vistos como distantes do que é comumente aceito como uma religião e nem eles mesmos se reconhecem como religiosos. Esses movimentos poderiam ser incluídos no rol das religiões? Este artigo procurou compreender o elemento religioso presente nas práticas da Nova Era, também chamadas de novas espiritualidades. Foram levantados quatro exemplos de grupos e práticas individuais com o objetivo de perceber o que as tornam religiosas: o Espaço Arthurianno, a Escola de lluminação de Ramtha, o Movimento Pró-Vida e a prática da ioga e meditação. A noção de religião foi discutida à luz do conceito estabelecido por Wouter Hanegraaff a partir da definição clássica de Geertz. A utilização de determinados conceitos de religião é o que faz dessas práticas exemplos de religião na sociedade atual, demonstrando que o religioso vai muito além daquilo que é usualmente reconhecido como tal.
\end{abstract}

Palavras-chave: conceito de religião; natureza da religião; novos movimentos religiosos; novas espiritualidades; nova era.

\begin{abstract}
Studies of the New Religious Movements raise questions about the nature of religion. Many of these movements can be seen as far from what is usually accepted as a religion and neither they recognize themselves as religious. Could these movements be included in the roll of religions? This paper aims to understand the religious element that is present in the New Age practices, also called new spiritualities. Four examples of groups and individual practices were raised in order to understand what make them religious: the Arthurian Space, the Ramtha School of Enlightenment, the Pro-Life Movement and the practice of yoga and meditation. The notion of religion was discussed in the light of the concept established by Wouter Hanegraaff from Geertz's classical definition. The use of certain concepts of religion allowed perceiving those practices as examples of religion in modern society, demonstrating that religion goes beyond what is usually recognized as such.
\end{abstract}

Keywords: concept of religion; nature of religion; new religious movements; new spiritualities; new Age.

\footnotetext{
Artigo recebido em 30 de junho de 2014 e aprovado em 24 de Setembro de 2014.

* Doutor em Antropologia. Professor na Pontifía Universidade Católica de São Paulo (PUC/SP). País de origem: Brail. E-mail: silasg@pucsp.br.
} 


\section{Introdução}

Estudos sobre os Novos Movimentos Religiosos e sobre a Nova Era, mais especificamente, geram algumas inquietações para aqueles que se preocupam com a religião em seu sentido mais amplo. Quando estamos diante de manifestações religiosas tradicionais, como as grandes religiões históricas e socialmente numerosas, não nos damos conta da dificuldade de compreensão do fato religioso que se manifesta incessantemente como novas formas e conteúdos. As grandes religiões são inquestionavelmente religiões. Mas e os pequenos grupos, que muitas vezes nem se reconhecem como religiosos, podem ser incluídos no rol das religiões? O que faz das ideias e das práticas de um grupo de pessoas que meditam regularmente uma religião? Essas práticas poderiam ser objeto de estudo da Ciência da Religião, embora seus praticantes não se reconheçam como pessoas religiosas? Como pode ser classificada a prática da ioga realizada em academias de ginástica, tão distante de qualquer elemento notoriamente classificado como religioso? Onde termina a característica de ser religioso e começa a de ser um grupo com ideias apenas filosóficas (ou vice-versa)? Aos olhos dos fiéis essa questão pode parecer menor, embora seja muitas vezes atravessada por posturas ideológicas e discriminatórias. Ao estudioso de religião trata-se de algo profundamente instigante, pois põe em xeque os limites da própria Ciência da Religião. Afinal, o que pode ser considerado religioso e, portanto, passível de ser objeto dessa ciência e o que não cabe como tal?

Este artigo procura refletir sobre a própria conceituação de religião no interior das Ciências da Religião a partir de alguns exemplos retirados da infinidade de agrupamentos sociais e de instituições das mais diversas que poderiam ser enquadradas no que a literatura define como Novos Movimentos Religiosos (BARKER, 1989; GUERRIERO, 2006). Num primeiro momento apresentaremos as características dos casos selecionados mais significativas aos nossos objetivos. Convém ressaltar que alguns deles não formam propriamente um 
movimento social, mas podem ser incluídos na denominação de NMR (Novos Movimentos Religiosos), pois compõem, de alguma maneira, um grupo de pessoas em torno de objetivos comuns a partir de crenças e concepções compartilhadas de ordem geral da existência. A escolha desses movimentos se deu a partir de alguns critérios, como o fato de estarem aparentemente distantes do que se costuma compreender, no senso comum, por religião, e principalmente pela autodefinição de movimentos não religiosos, mas filosóficos, científicos ou, no limite, espiritualistas. Dados os limites desse estudo, selecionamos apenas quatro casos, entre alguns mais antigos e outros recentes, entre estrangeiros e brasileiros, entre alguns fortemente institucionalizados e outros bastante flexíveis e individualizados e entre aqueles mais visíveis e conhecidos no espaço público daqueles pouco conhecidos, independentemente de serem reconhecidos ou não como manifestações da Nova Era. Não foi nossa preocupação traçar mais detalhadamente as características sociológicas e históricas desses grupos, o que requereria estudos de caso mais aprofundados. Detivemo-nos nos discursos e elementos simbólicos que pudessem indicar certo grau de religiosidade presente e que permitissem perceber um padrão comum a todos eles e que indicassem, ao nosso recorte, o elemento religioso comum. Assim, foram selecionados o Espaço Arthurianno, a Escola de Iluminação de Ramtha, o Movimento Pró-Vida e a prática da ioga e meditação. Nossas fontes de informações foram os sites institucionais de tais movimentos encontrados na Internet, panfletos de divulgação e programas de rádio também utilizados como mecanismos de divulgação.

Após a apresentação desses movimentos, faremos algumas ponderações acerca da polêmica do conceito religião e por fim buscaremos analisar o fundamento religioso ali contido em busca da ampliação da nossa compreensão sobre a religião em geral. 


\section{Diferentes maneiras de vivenciar a religião}

A dimensão histórica da Ciência da Religião, também conhecida como vertente empírica, tem registrado inúmeras maneiras diferentes de se vivenciar aquilo que podemos entender por religião. Sem querer entrar, agora, na própria conceituação do que seja religião (o que levaria a muitas dessas práticas serem eliminadas de imediato), vamos procurar levantar elementos dos discursos de alguns movimentos mais distanciados das religiões tradicionais para poder, posteriormente, compreender se podem ou não ser chamados de religiosos. Começamos com um típico representante de movimento da Nova Era.

O Espaço Arthurianno é um local que oferece diferentes serviços em prol de uma "transformação individual". Tipicamente um empreendimento da Nova Era, o Espaço Arthuriano pode ser classificado como um "Centro Especializado", segundo as definições de Magnani (1999, p. 27). Localiza-se na zona norte de São Paulo, num bairro típico de classe média, com forte presença de serviços relacionados a curas alternativas. O grande slogan do Espaço Arthurianno é "a cura através do amor". A especialidade do local é o desenvolvimento de atitudes de seus clientes que levem à transformação do indivíduo como um todo (ESPAÇO ARTHURIANNO, 2014a). O espaço existe há aproximadamente dez anos e foi formado por um grupo de quatro curadores que oferecem cursos e tratamentos em radiestesia, radiônica, numerologia, reike, florais, massoterapia, tarô e outros oráculos. Justificam que através da apometria promovem um autoconhecimento, despertando em cada um o seu poder de cura. Apometria é o nome atribuído a um conjunto de técnicas terapêuticas de cunho espírita com ênfase na projeção da consciência, ou experiências fora do corpo físico, e na harmonização dos denominados corpos sutis. A apometria já existe, no meio espírita, desde a década de 1960. No entanto, nas últimas décadas avançou pelo campo das práticas da Nova Era e recebe até adjetivações como apometria quântica, numa menção direta ao campo da física subatômica, termo muito empregado por praticantes do meio. 
Enfatizam que a apometria não tem cunho religioso. O discurso utiliza categorias que se aproximam de uma ciência, embora não seja a ciência reconhecida academicamente.

Nesse espaço são oferecidos cursos que visam não apenas a formação de futuros terapeutas na área como também a apresentação das técnicas de cura a pessoas interessadas e que, a partir de então, serão direcionadas aos tratamentos específicos. Uma especialidade do local é a consulta através da mesa quantiônica arcturiana. Trata-se de um procedimento que visa avaliar o estado vibracional do paciente, tanto no nível físico como no emocional, mental e espiritual. Há um discurso que se assemelha ao da psicanálise, muito embora não haja qualquer menção a ela. Busca-se, através dessa mesa quantiônica, trazer para o consciente do indivíduo, as memórias registradas inconscientemente e que estão causando desequilíbrio no seu campo energético. Explicam que a mesa quantiônica (em alguns momentos apresentada simplesmente como mesa quântica) é uma aplicação da radiestesia em conjunção com a física quântica e as energias dos cristais. As categorias de energia, campo energético, corpo sutil, além da física das partículas, são muito correntes no meio e serão analisadas na terceira parte desse trabalho. A mesa quantiônica arcturiana, que é vendida aos interessados, possibilitaria não apenas o diagnóstico do desequilíbrio energético, como também um "realinhamento total de chakras e de corpos sutis, revelando para o individuo sua missão, de acordo com sua cor de aura e suas potencialidades e desafios”. (ESPAÇO ARTHURIANNO, 2014b).

O nome do local faz uma alusão direta ao mito arthuriano. No entanto, o grande mito de fundo desse grupo é o do povo arcturiano. $\mathrm{O}$ rei Arthur teria sido uma encarnação de um mestre arcturiano. A crença nos arcturianos é compartilhada com vários grupos, como a Fraternidade Branca Universal, a Fraternidade Saint Germain, o grupo Anjos de Luz entre outros. Dizem que da estrela Arcturus, ou Arturo, uma das mais brilhantes estrelas do firmamento, teriam vindo os arcturianos. Esses seres extraterrestres estariam aqui para proteger a nossa civilização e para nos auxiliar no processo de evolução a que estaríamos 
destinados. O conhecimento científico e espiritual dos arcturianos é, para esses grupos, um dos mais avançados do universo.

O Espaço Arthurianno tem programas em horário fixo semanal na Rádio Mundial de São Paulo (FM, 95.7 Mhz). No programa, ao vivo, os terapeutas arthuriannos respondem as perguntas feitas por ouvintes e divulgam seus produtos, como cursos e técnicas terapêuticas.

A Rádio Mundial foi fundada no início da década de 1990. Desde 1999 é dedicada exclusivamente à transmissão de uma programação esotérica voltada para a autoajuda. Essa rádio tem uma grade de programação fixa, o que demonstra sua grande aceitação junto ao público. Os espaços são, em sua maioria, vendidos a pessoas ou grupos que querem divulgar atividades do campo da espiritualidade e curas terapêuticas alternativas. Na programação, encontramos uma infinidade de grupos esotéricos e de autoajuda, muito próximos ao perfil selecionado para esse nosso estudo (Cf. RÁDIO MUNDIAL, 2014c).

O segundo grupo escolhido como exemplo foi a Escola de Iluminação de Ramtha. Trata-se de um movimento criado pela norteamericana JZ Knight na década de 1970. Ramtha teria sido um guerreiro no lendário continente de Lemúria há 35 mil anos. Para seus seguidores, Ramtha usou a observação, a reflexão e a contemplação de si mesmo para aprender os segredos da imortalidade e se tornar iluminado e um grande mestre espiritual. Dizem que há vestígios de seu ensinamento nos achados arqueológicos da Índia e do Egito antigos. Ramtha teria voltado, neste momento, para intervir nos acontecimentos da humanidade, utilizando JZ Knight como canal de manifestação, porque a humanidade estaria apta, agora, a "descobrir nossa verdadeira identidade como observadores, responsáveis por colapsar o campo quântico e moldar o tempo e o espaço” (ESCOLA DE ILUMINAÇÃO DE RAMTHA, 2014a).

Os ensinamentos de Ramtha foram bastante divulgados há alguns anos por 
meio de um filme de muito sucesso na Internet: Quem somos nós, uma produção norte americana de 2004, dirigida por Willian Arntz. No entanto, o filme não deixa claro que se trata do espírito de Ramtha se manifestando através de uma canalização. JZ Knight aparece como uma espécie de narradora de um documentário que procura utilizar elementos da física quântica para explicar acontecimentos peculiares na vida de uma personagem. São usados depoimentos de cientistas, envolvidos ou não com espiritualidade, que acabam dando uma conotação científica ao filme. A grande mensagem de fundo é a de que qualquer um de nós pode modificar a realidade à nossa volta.

Correlatos a esse filme surgiram na mesma época outros filmes e livros que tratavam basicamente da mesma questão. O mote central de todos girava em torno daquilo que ficou conhecido como "lei da atração". Esta pode ser entendida como um mito recorrente nesse meio. Diz a lei da atração que os pensamentos das pessoas, tanto conscientes como inconscientes, ditam a realidade de suas vidas. Se uma pessoa deseja alguma coisa, basta acreditar que é possível e assim acabará conquistando-a. O inverso também é verdadeiro, ou seja, se pensar em algo que não deseja isso acabará acontecendo. Há uma variação desse mito que é, talvez, mais usual no meio. Trata-se do chamando "pensamento positivo".

Os ensinamentos de Ramtha são sintetizados em quatro pilares centrais. $\mathrm{O}$ principal diz respeito à afirmação "você é Deus". Em seguida é enfatizado que podemos conhecer tudo aquilo que ainda está desconhecido. O terceiro, aquele já citado acima, fala que a consciência e a energia criam a natureza da realidade. Resta, por fim, a mensagem de que cada um é responsável pela conquista de si mesmo, sendo esse um desafio incontornável no nosso processo evolutivo. No próprio site é destacada uma fala de Ramtha afirmando que "não existe nenhuma voz que lhe ensine melhor que a sua. Você é o seu próprio salvador. Você é o seu próprio mestre" (ESCOLA DE ILUMINAÇÃO DE RAMTHA, 2014b).

A página da Internet que divulga esses ensinamentos não se furta a afirmar, insistentemente, que JZ Knight não é uma fraude e que vários cientistas que 
assistiram a suas palestras e canalizações do espírito de Ramtha comprovam a veracidade do processo. Há várias indicações de testes científicos que teriam sido empregados para examinar a canalização de Ramtha através de JZ Knight. Destacamos a recorrência à ciência, tanto no conteúdo dos ensinamentos quanto na comprovação da veracidade, garantida pelo conhecimento científico, afastando qualquer suspeita de que tudo não passaria de uma fraude.

A Escola de Iluminação de Ramtha funciona basicamente com eventos e vivências em torno da sua fundadora, JZ Knight, que profere cursos e palestras em várias localidades. Como dizem seus adeptos, não se trata de JZ Knight, mas do próprio Ramtha que vem nos iluminar. Pela primeira vez um desses eventos ocorreu no Brasil, na cidade de Atibaia, estado de São Paulo, em 2014. Nesse tipo de evento, as pessoas ficam quatro dias uma espécie de retiro enquanto recebem os ensinamentos e têm a possibilidade de praticá-los experimentalmente.

Novamente aqui encontramos o discurso de que tudo isso não é uma religião, mas uma ciência em busca da elevação do ser humano.

O terceiro exemplo selecionado foi o do Movimento Pró-Vida. É muito comum vermos no vidro traseiro de muitos veículos um triângulo com a seguinte expressão: "Se você já estiver preparado, uma Força Maior o levará à Pró-Vida". Interessante é notar que a expressão "Força Maior” aparece em letras maiúsculas, conotando uma ideia de que existe algo maior, superior, e que o sujeito que lê a mensagem poderia alcançá-lo. É importante também ressaltar a referência de que há um momento certo, quando "você já estiver preparado", indicando que não é para qualquer pessoa, mas para as escolhidas. Essa é uma característica muito comum dos Novos Movimentos Religiosos (WILSON, 1970). Podemos supor que alguém que esteja inclinado e disposto a encontrar esse algo superir poderá se sentir tocado pela mensagem e procurará a instituição.

A Pró-Vida foi uma idealização e criação de um médico paulista em 1978. 
Muito semelhante em seus fundamentos filosóficos a outros movimentos anteriores e mais conhecidos, como a Ordem Rosa Cruz e a Maçonaria, traz elementos novos, esteticamente mais modernizados e numa linguagem acessível a um público participante do mercado de consumo e ávido por uma "sabedoria superior". Atinge uma parcela da população bastante elitizada e escolarizada. Identifica-se como um movimento filosófico iniciático que "se propõe a conduzir pessoas interessadas a reconhecer e despertar o enorme potencial de suas capacidades mentais, psíquicas e espirituais” (PRO-VIDA, 2014a).

A Pró-Vida cresceu de maneira consistente desde sua fundação e não foi abalada, ao menos externamente e em termos relativos à sua presença na paisagem urbana, pela morte de seu fundador, em 1981. O movimento é liderado por familiares do médico Celso Charuri. Seus ensinamentos são transmitidos por meio de publicações e palestras gravadas do início do movimento. Hoje há sedes da instituição em mais de sessenta cidades brasileiras e outras em oito países da América do Sul, do Norte e Europa. Além dessas localidades, onde são oferecidos os cursos iniciáticos, há três clubes de campo no Brasil e outros na Argentina e Bolívia. Nos clubes, o iniciado é estimulado a viver integralmente em harmonia com os ensinamentos da ordem. Enfatiza-se a formação gradual por meio de um treinamento e desenvolvimento mental, por níveis de formação. São nove os níveis sequenciais, cada um composto por cursos, palestras, exercícios, treinamentos mentais e discussões do tema, pautados sempre pelo método concebido pelo fundador. Ressaltam que esses ensinamentos estão abertos a qualquer interessado, independentemente de religião ou credo.

No discurso da Pró-Vida não há referências a seres superiores. Em poucas passagens falam num Deus, que bem pode ser o Deus cristão, mas não há ênfase nisso. No entanto, o grande destaque é a ampliação da consciência, "até chegar "à consciência Cósmica e empreender um caminho em direção à Verdade, aquela que deve existir e que é Suprema e Absoluta ao nível de todos os possíveis relativos. Por isso nos intitulamos Pró-Vida - Integração Cósmica” (PRÓ-VIDA, 2014b). Celso Charuri afirma que o grande objetivo é alcançar a imortalidade e que, para tanto, é 
preciso descobrir os Princípios Absolutos. "Neste dia, morrerá para a carne, efêmera, e viverá para o Espírito, Eterno. Será Imortal.” (CHARURI, 2014).

Chegamos, agora, ao nosso último caso selecionado como exemplo, e talvez aquele que traz mais desafios ao propósito deste artigo. Trata-se da prática da ioga ${ }^{1}$. Convém observar que a ioga, atualmente, auferiu um perfil bastante secularizado, sendo empregada em academias de ginástica ou até mesmo como objeto de estudos clínicos que buscam comprovações materiais para sua eficácia. Esse campo é extremamente amplo e seria impossível abarcar toda a imensa diversidade existente. Nossa preocupação é a de, a partir de alguns exemplos, perceber elementos de cunho religioso na prática da ioga realizada por pessoas que não se reconhecem necessariamente como religiosas. $\mathrm{Ou}$, melhor dizendo, não praticam a ioga como vivência religiosa.

Pamela Siegel, em sua tese sobre o uso da ioga no Sistema Único de Saúde (SUS), afirma que esta tem, ainda hoje, forte vínculo religioso, sendo praticada em inúmeros NMR (SIEGEL, 2010, p. 53). Diz ainda, que para além de movimentos estritamente religiosos, a ioga sofreu um processo de secularização e passou a ser praticada como uma atividade física. Mesmo nesses casos a ioga praticada visa um bem estar integral do sujeito, unificando corpo e mente. Em muitos dos casos, é utilizado o termo espiritual como uma busca de evolução mental relacionada com energia e expansão da consciência (SIEGEL, 2010, p. 74-95). Outra ampliação do uso da ioga pode ser percebida em estudos da área da saúde que buscam compreender a meditação, a partir da ioga ou similares, como complemento do tratamento de distúrbios cardiovasculares, hipertensão, estresse e depressão (KOZASA, 2006; MENEZES \& DELL'AGLIO, 2009). Esse uso mais secularizado não elimina possíveis referências às categorias advindas do próprio meio nova era, como energização, integração e harmonia corpo-mente e pensamento positivo.

\footnotetext{
${ }^{1}$ Optamos por utilizar o termo ioga no gênero feminino, forma habitual de incorporação dessa palavra em nossa língua desde o final do século XIX. Há correntes dentre os praticantes que defendem o uso de yôga. Trata-se, muito mais, de divergências dentro do próprio campo.
} 
Nossa questão é saber se o exercício da ioga e da meditação pode ou não ser entendido como uma prática religiosa. Impossível saber, sem um levantamento que compreendesse as diferentes formas como a ioga é vivenciada, se em todos eles podemos ou não encontrar vestígios religiosos. Vamos apenas nos ater a alguns casos específicos que podem ser indicativos de recorrências mais amplas. Não são poucas as pessoas que buscam manuais de como meditar e que, a partir desse referencial, praticam a ioga em suas próprias casas ou em pequenos grupos. Para tanto, voltemo-nos a um ensinamento veiculado também pela Rádio Mundial.

Otávio Leal é apresentador de dois programas: “Aos pés dos mestres”, transmitido semanalmente, e outro, em conjunto com a monja Coen, conhecida líder do meio budista (RÁDIO MUNDIAL, 2014a). Neste programa, Leal, que se apresenta como dirigente de uma ordem iniciática tântrica, procura transmitir algumas técnicas para que o ouvinte siga e atinja a iluminação. Inicia dizendo que um iogue verdadeiro faz tudo no seu dia-a-dia de acordo com os elementos da ioga. Sugere que se incorpore ao cotidiano a prática da meditação. Para ele, a meditação é uma maneira de alcançar a iluminação e provoca prazer e bem estar por meio do equilíbrio entre corpo, mente e emoções. Recomenda que se escolha um local sossegado e agradável em que possa andar em silêncio. Aqui, o andar é uma forma de meditação e não uma maneira de se chegar a algum lugar. O que se busca é um lugar interior. Diferente das técnicas tradicionais de ioga com posturas muitas vezes inacessíveis aos ocidentais de hábitos sedentários, esse apresentador de ioga pelo rádio sugere que simplesmente se ande. Nessa caminhada deve-se deixar de lado toda e qualquer preocupação e ansiedade, "aquietando a mente no fluxo da vida”. Ensina as técnicas de respiração, adaptando-as às passadas do caminhar e ao mesmo tempo mentalizando: “paz na Terra, paz em mim”. Acredita que através dessa mentalização o praticante enviará felicidade a todos os seres vivos. Por fim, é claro ao afirmar que as técnicas até então empregadas não são nada em si mesmas, mas o que é realmente importante é a conscientização do aqui e agora. Essa última expressão é bastante repetida no universo nova era e aponta para a crença de que a pessoa precisa estar centrada e equilibrada para poder alcançar a plenitude e promover a elevação, como veremos mais adiante. 
Dando legitimidade à sua fala, Leal se remete a um mestre zen do Japão, Moriyama Roshi, que diz: "Quando andamos assim, não temos pressa, pois nós já chegamos! Lembre-se, o primeiro passo já é o Último!" (RÁDIO MUNDIAL, 2014b). Seguindo a linha de ensinamentos mestre-discípulo, comum no budismo, Leal continua citando o seu mestre iogue que afirma estar na prática da meditação o encontro do êxtase da experiência do divino.

Ressalte-se, aqui, que esse divino não é personalizado, mas um divino que pode ser confundido como uma centelha interior que pode ser acesa, ou alimentada com a meditação e a ioga.

Neste exemplo retirado da programação da Rádio Mundial pode-se perceber como aquilo que denominamos ioga recebe uma infinidade de interpretações e é praticado das mais variadas maneiras. Há adaptações e ressignificações que levariam vários outros adeptos a não mais reconhecê-las como ioga. Otávio Leal é apenas um exemplo de como essa prática milenar pode ser reinventada e recriada a cada momento. Essa é apenas uma das múltiplas possibilidades de vivência da ioga. Nosso problema não é verificar o que os praticantes de cada uma das inúmeras variações compreende por ioga. Interessa-nos retirar alguns elementos que são comuns e que podem nos indicar o sentido religioso dessas vivências. Entendemos que esse tipo de ensinamento é muito comum a vários outros grupos praticantes de ioga. O eixo central está no fato de que cada um pode vivenciá-la a partir das suas condições e compreensões desse sistema. A tradição aparece e é importante, mas a adaptação é perfeitamente aceitável. O que permite a recriação e a permanência do sentido da ioga é justamente sua centralidade na compreensão de que o divino é encontrado no interior do próprio indivíduo. Assim, é possível traçar diferentes caminhos exteriores, pois o que realmente conta é o caminho interior.

Comparando com outras praticas da ioga, mais voltadas às posturas corporais e menos inclinadas a um desenvolvimento espiritual, podemos reconhecer como impossível generalizar e afirmar que a ioga é religião. A depender 
do contexto em que é praticada e da própria maneira como é encarada pelos seus adeptos, a ioga pode ser ou deixar de ser religião. No entanto, o que nos interessa, nos limites desse artigo, é perceber que em muitas ocasiões a ioga pode ser compreendida como uma vivência religiosa. Esses momentos dizem respeito à maneira como a ioga é reconhecida. Para muitos, a ioga permite uma integração entre a mente, o corpo e o espírito de seus praticantes. Quando compreendida dessa maneira, pode-se perceber que há uma noção espiritual e uma referência a uma realidade suprassensível, pois estaria conectada a uma mitologia própria da Nova Era, conforme veremos mais adiante.

Feitos esses breves levantamentos dos discursos desses quatro movimentos, podemos passar a analisá-los sob a ótica da Ciência da Religião no sentido de poder considerá-los ou não como movimentos religiosos (no sentido de Novos Movimentos Religiosos) e, consequentemente, questionar nossa própria compreensão sobre o que é ou não religião. Antes, porém, faremos algumas breves ponderações sobre o conceito de religião.

\section{Dificuldades na definição de religião}

A compreensão do que é religião pode variar enormemente dependendo da perspectiva em que nos encontramos. Para um crente e fiel praticante essa discussão parece não fazer sentido. Afinal, para ele a religião é algo tão absoluto quanto óbvio. É muito comum ouvirmos dos fiéis explicações como: "religião é o contato com Deus", ou "relação com as coisas do Alto", ou ainda "é o contato com o Sagrado". Esse "Deus" ou esse "Sagrado" são entidades absolutas, totalmente diferentes. A experiência religiosa pode ser tão intensa que se torna evidência inequívoca dessa força maior. De maneira geral, tais definições caberiam à maioria das religiões. Acrescenta-se a isso o fato de que é bastante comum, entre nós brasileiros, a concepção de que as diferentes religiões seriam diferentes caminhos para se atingir esse mesmo sagrado. Esses caminhos seriam, portanto, relativos, enquanto que o sagrado estaria sempre numa concepção de absoluto. Alguns 
estudos apontam para um substrato religioso comum na sociedade brasileira, o que poderia, em certo sentido, atestar essa visão generalizada (NEGRÃO, 2009; BITTENCOURT, 2003; DROGERS, 1987). Esse substrato é a crença num absoluto comum a todos, independente dos diferentes caminhos que levariam até ele.

Para William Paden (2001), a religião é resultado de uma perspectiva e pode ser vista por ângulos bastante diversos e até opostos (PADEM, 2001, p. 13). Ao lado da perspectiva do crente podemos acrescentar uma perspectiva externa, analítica, que também pode conter diferentes posturas, a depender do posicionamento metodológico e teórico daquele que se está analisando. Não há qualquer pretensão de se estabelecer uma posição final e definitiva. Isso seria ingenuidade. Mas é preciso deixar claro de que ponto de vista estamos falando.

Se quisermos explicar a religião a partir das vivências dos fiéis podemos permanecer em explicações êmicas ${ }^{2}$ e definir o que é religião a partir da perspectiva da fé. Essa posição não interessaria ao cientista da religião e nem resolveria a nossa indagação sobre o que torna uma prática ou uma ideia algo religioso. Além do mais, as posições internas às religiões costumam discriminar todas as demais que não cabem nas suas próprias concepções. A velha expressão "magia é a religião do outro!" faria sentido aqui. Outra consequência dessa posição é a assumida pelos próprios praticantes. Percebemos que praticamente em todos os nossos exemplos há ênfase em não serem reconhecidos como religião. A questão do reconhecimento identitário é importante e deve ser considerada ao se estudar qualquer um desses casos. No entanto, se ficarmos presos a ela não avançaremos na nossa preocupação de compreender o que leva esses movimentos e outros similares a serem religiosos.

Essas novas formas de espiritualidade nos colocam diante desse desafio. Será que podemos considerar todas elas numa mesma categoria de religião, juntando realidades tão distintas? Até mesmo na conceituação de Novos

\footnotetext{
2Estamos utilizando a distinção êmico/ético no sentido de uma visão "de dentro" e outra "de fora", respectivamente.
} 
Movimentos Religiosos alguns casos poderiam ser questionados, como é o da prática da ioga.

Corremos o risco de tornar nossa visão tão ampla que dentro dela tudo caberia. Uma conceituação de religião dessa natureza poderia nos ser de pouca utilidade. Citamos aqui a abertura possível, e que vários estudiosos fazem, para as categorias de religiões seculares ou outras terminologias correlatas, como religião implícita ou até mesmo religião civil (CRUZ, 2013). Aspectos da vida secularizada podem ser compreendidos como eventos religiosos na medida em que carregam uma "efervescência coletiva" e funcionariam analogamente a uma religião. Nessa conceituação caberiam os grandes eventos esportivos, o mercado econômico e até mesmo rituais jurídicos e ideologias políticas. Convém deixar claro que essa é uma perspectiva possível para se estudar tais manifestações da vida social, mas está distante da nossa perspectiva no presente estudo. Queremos dar alguns passos na compreensão do que torna algo religioso, sem, no entanto, recorrer à ideia êmica de isso se dever ao "toque do sagrado" ou mesmo ampliar de tal maneira nosso conceito que dele nada poderíamos aferir. É preciso afinar nossa conceituação.

Outra questão aqui envolvida diz respeito à relação ciência e religião. Não é nossa preocupação discutir esses aspectos, embora seja de fundamental importância para a compreensão dos campos de saberes. Nosso olhar está voltado para o conteúdo dos discursos desses movimentos e, estes estão repletos de analogias com o campo científico. O importante é ressaltar quais elementos retirados de discursos científicos são utilizados na lógica religiosa. Mais ainda, a ciência tem uma reputação na sociedade contemporânea de detentora de uma verdade comprovada e isso passa a ser utilizado por vários desses movimentos como forma de legitimação de suas concepções de mundo.

Mas, afinal, o que é religião? Há inúmeras definições do conceito. Nenhuma delas definitiva ou completa. Se, aos olhos do fiel a religião pode ser definida pelo "toque do sagrado", ao estudioso isso não basta. Até onde vai a religião, independentemente da definição dada pelos próprios agentes? A definição de 
religião já foi muito discutida e questionada. Para alguns, tratava-se de uma concepção ocidental e colonialista, que enxergava como religião apenas aquelas organizações institucionalizadas, compostas por tradição, doutrina, corpo sacerdotal e rituais. Ajudava, ainda, o fato de terem suas tradições registradas em livros sagrados. Essa era a visão dominante na época do Colonialismo. Ao afirmar que os europeus tinham religião, estava estabelecido que os nativos, das terras colonizadas, possuíam no máximo magia e superstição (SALER, 2008). Tal fato demonstraria a superioridade europeia sobre os demais povos. O caráter ideológico do conceito passou a ser motivo para a proposta de sua eliminação. (SALER, 2008, p. 219). Borg afirma que não há definição de religião isenta de propósitos, levantando suspeitas pela continuidade do próprio uso do termo entre os estudiosos (BORG, 1999, p. 405). O caráter judaico-cristão também é enfatizado como mais um motivo para o abandono do conceito. Alega-se que em outras línguas não há qualquer expressão que possa ser traduzida por religião. Schilbrack enfatiza um aspecto que nos é particularmente interessante. Afirma que é possível empregar o termo religião mesmo quando as pessoas do grupo estudado não o utilizem (SCHILBRACK, 2010, p. 1122). A questão é saber interpretar algo realizado pelo grupo estudado como sendo religioso. A definição de religião é fundamental para esse autor. O importante é saber se a definição adotada ilumina ou distorce a prática que está sendo investigada (SCHILBRACK, 2010, p. 1123).

Embora possamos reconhecer o viés ideológico do termo religião, ou ainda que não haja em muitas línguas um termo correlato, reconhecemos que, independente disso tudo, religião é um fato. Ou seja, pessoas e grupos constroem suas vidas e criam suas concepções e visões de mundo pautados em aspectos que podemos chamar de religião. É uma constatação antropológica de que não existe qualquer grupo social que não disponha de um sistema de crenças que poderíamos definir como mágico-religioso. Além disso, não estamos separando religião de magia, embora, em termos sociológicos, possamos encontrar algumas especificidades. Religião e magia partem de um mesmo substrato, o das crenças. 
Estamos acostumados a perceber na Ciência da Religião duas posturas mais amplas acerca da definição de religião (HOCK, 2010; PASSOS e USARSKI, 2013). De um lado podemos alocar as visões substantivistas e ontológicas, aquelas que partem do princípio de que há um elemento sui generis na religião (TERIN, 1998). Essa corrente tem uma forte herança do pensador alemão Rudolf Otto e dos trabalhos de Mircea Eliade. Este último empreendeu um esforço eloquente de encontrar um substrato religioso nas diversas manifestações religiosas da história da humanidade. Esse substrato, porém, é visto como uma essência, um sagrado que se manifesta de diferentes formas por meio das hierofanias. Em geral, os adeptos dessa postura tratam com muita naturalidade do termo sagrado como se fosse inequívoco.

De outro lado, temos as visões mais funcionalistas, que buscam compreender as funções que a religião tem nas formações sociais. Um grande mentor desta postura pode ser identificado na figura do sociólogo francês Emile Durkheim.

Há, sem dúvida, uma infinidade de variações teóricas em cada uma dessas posturas. O que convém ressaltar é que enquanto aqueles primeiros apontam para uma essência substantivista do religioso, independente do ser humano, os últimos assinalam as diferentes construções sociais em que a religião participa. Teríamos assim um sagrado mais no sentido de um adjetivo. Os funcionalistas fogem rapidamente da possibilidade de pensar a religião no singular afirmando que só podemos perceber a religião nas suas mais diferentes manifestações históricas. Seriam mais religiões, sempre no plural, do que uma religião no singular, que pudesse apontar para algum tipo de essência. Carecemos, ainda, de uma definição que possa perceber a universalidade da religião sem, necessariamente, explicá-la a partir de pressupostos metafísicos.

Antes de passarmos à análise dos nossos exemplos, convém discutir um pouco mais acerca da distinção entre religião e espiritualidade, tão cara nesse meio e bastante útil no nosso caso. Paul Heelas e Linda Hoodhead realizaram uma ampla 
pesquisa sobre as mudanças da religião na sociedade inglesa (HEELAS; WOODHEAD, 2005) e perceberam que é possível distinguir três diferentes tipos de religião dentro de um amplo espectro de relacionamentos que o ser humano estabelece entre si mesmo, a ordem natural e aquilo que compreende como divino ou sagrado. Num primeiro tipo, localizado em um dos extremos do espectro, identificaram as denominadas religiões de diferença. Nas quais há uma clara distinção entre Deus, o ser humano e a natureza. A salvação está nas mãos de Deus. A visão dualista tradicional das religiões judaica e cristã caberia perfeitamente aqui (HEELAS; HOODHEAD, 2005, pp. 15-18). Num segundo modelo estariam as religiões de humanidade. Nelas, os três elementos, divino, humano e natureza, estariam em certo equilíbrio. São congregações com posturas mais abertas e liberais que oferecem certo grau de liberdade e tolerância. A ênfase moral recai sobre o cuidado com os outros e a caridade. A salvação ainda está nas mãos divinas, mas a ação humana pode alterar o nosso destino. Segundo os autores, muitas vivências do próprio cristianismo caberiam nesta definição (HEELAS; HOODHEAD, 2005, p. 18). No outro polo do espectro temos as espiritualidades de vida. Para eles, as três modalidades coexistem, mas essas últimas, as espiritualidades, estão ganhando cada vez mais espaço na sociedade inglesa. De certa maneira podemos perceber um paralelo desse caso concreto com as demais sociedades modernas ocidentais, entre elas a brasileira, como apontam os casos levantados para esse estudo. Nas espiritualidades de vida encontramos uma relação intrínseca entre a espiritualidade da pessoa e uma espiritualidade integral da natureza e da ordem da realidade última. O divino estaria associado, de maneira holística, ao indivíduo e à natureza. A ênfase salvacionista recai no indivíduo. Em geral não utilizam o termo salvação, pois o que conta para essas espiritualidades é a evolução do indivíduo, ou self (HEELAS, 1997). Esse pode empreender um caminho em busca do seu "eu interior", no sentido de uma evolução espiritual e integração com o divino, ou pode decair e ficar apegado ao seu próprio ego. Cabe ao indivíduo encontrar a "plenitude da existência", termo comumente empregado no meio. Para os autores, as espiritualidades de vida podem ser encontradas em várias 
manifestações, como a mística oriental praticada no Ocidente, o movimento de contracultura da década de 1960, o romantismo do século XIX, a teosofia, o movimento da Nova Era, o neopaganismo e outros.

$\mathrm{Na}$ mesma linha, o sociólogo Colin Campbell encontrou as raízes do que chamou de cultic milieu no próprio romantismo oitocentista (CAMPBELL, 2001), que indicava a existência da criatividade humana como uma expressão de uma força sobrenatural presente em todo mundo natural e dentro de cada indivíduo. A arte romântica continha, portanto, um aspecto divino. Havia ainda o drama da salvação e redenção representado nos limites do próprio ego. Isso tudo levou a uma tendência ao misticismo introvertido (CAMPBELL, 2001, p. 257). Esse cultic milieu se estenderia até os dias atuais, permitindo a manifestação das mais variadas formas de espiritualidade que focam a experiência e a evolução individuais. Heelas e Hoodhead denominaram por milieu holístico algo semelhante ao cultic milieu de Campbell. É nesse caldo cultural de meio holístico que surgem as mais diferentes formas de espiritualidades de vida.

Ainda na distinção entre religião e espiritualidade entendemos que a definição dada pelo cientista da religião e historiador holandês Woulter Hanegraaff (1999) avança de maneira significativa a nossa compreensão sobre esse universo das novas religiões ou espiritualidades.

Hanegraaff parte da famosa definição de religião como um sistema cultural de Clifford Geertz, muitas vezes citada em trabalhos acadêmicos (GEERTZ, 1978, pp.104-105). Sem negar a definição clássica, Hanegraaff subdivide o que ele entende por religião (no singular) por duas outras categorias: religiões (no plural) e espiritualidades. Embora seja um pensador que poderia ser identificado na vertente mais funcionalista, Hanegraaff não deixa de apontar para uma singularidade da religião sem cair em qualquer tipo de essencialismo. Se Geertz define a religião a partir de um sistema de símbolos que gera motivações e disposições nos indivíduos ao formular uma ordem de existência com total aparência de realidade, Hanegraaff vai além ao introduzir a necessária existência 
de um conteúdo metaempírico. Para ele, religião é qualquer sistema simbólico que influencia a ação humana oferecendo, através de rituais, uma possibilidade de contato entre o mundo cotidiano e um quadro metaempírico mais geral de significado (HANEGRAAFF, 1999a, p. 371). A partir dessa definição mais ampla, o autor esclarece que esses sistemas simbólicos se manifestam sempre em modelos empiricamente verificáveis que podemos defini-los como religiões (agora no plural) e espiritualidades.

Uma religião, entre as inúmeras possíveis, se caracteriza pelo fato do sistema simbólico estar sempre organizado sob a forma de uma instituição social. Assim, uma religião necessita inevitavelmente de um grupo articulado em torno de um conjunto de mitos, com hierarquia e papéis definidos, e de uma doutrina que manifeste ou demonstre um conhecimento sistematizado. Embora usualmente localizemos a religião apontada inicialmente (no singular) com essas formas de religiões (no plural), ela pode se manifestar naquilo que Hanegraaff denominou espiritualidades. Para ele, uma espiritualidade é qualquer prática humana que mantém contato entre o mundo cotidiano e um quadro metaempírico mais geral de significados por meio de manipulações individuais de sistemas simbólicos (HANEGRAAFF, 1999a, p. 372). O mais interessante, para os estudos da Nova Era, é que o autor diferencia as espiritualidades comuns do misticismo ocidental, como aquelas surgidas até o século XIX, das espiritualidades seculares, só possíveis de ocorrer após a secularização empreendida pela sociedade moderna (HANEGRAAFF, 1996). Enquanto as primeiras surgiam em um meio religioso, colhendo seus conteúdos a partir do referencial religioso tradicional, as últimas constroem seus sistemas simbólicos a partir de conteúdos seculares, como, por exemplo, da ciência moderna (HANEGRAAFF, 1996, p. 67-69).

O grande avanço que podemos tirar daqui é o fato de que há uma ampliação do conceito de religião sem, no entanto, desembocar numa generalização infecunda. $\mathrm{O}$ autor trabalha com uma definição de religião como um sistema de símbolos, portanto uma construção social, e remete esse sistema a um quadro 
metaempírico da realidade. Estaria aí o substrato do religioso. Portanto, teríamos sempre uma religião ou espiritualidade quando esse sistema simbólico influencia as ações cotidianas remetendo-as a um quadro metaempírico de significados. Vamos utilizar esse conceito para analisar os casos selecionados neste trabalho.

\section{Onde começa ou termina a religião}

Como visto anteriormente, para muitos, principalmente para seus praticantes, as novas espiritualidades estão muito longe de ser religião. A depender da perspectiva adotada, a noção de espiritualidade torna-se um problema a ser equacionado. Para muitas das conceituações de religião e de espiritualidade há uma resistência em se perceber as práticas da Nova Era, aqui apontadas, como expressões religiosas. Muitas perguntas permaneceriam. Os oráculos, como tarô e astrologia poderiam ser considerados no rol de espiritualidades? Por quê? E o pensamento positivo? Num primeiro momento tudo isso parece muito fugaz e distante de religião. Mas, seguindo a pista proposta por Hanegraaff, essas vivências podem auxiliar na compreensão do substrato religioso contido nos mais variados casos, sem cair numa visão substantivista ou essencialista.

Primeiramente, é preciso reconhecer que não estamos mais lidando com exemplos de religiões tradicionais, bem estruturadas, solidamente institucionalizadas e com uma carga de tradição evidente. Na sociedade atual (e a sociedade moderna brasileira não se diferencia em grandes moldes de outras sociedades ocidentais modernas e secularizadas) vivenciamos novas formas de religião. A secularização não significou uma evasão do fato religioso, mas modificou de maneira significativa as vivências religiosas. Uma explicação substantivista poderia justificar essa permanência do "sagrado". No entanto, optamos por procurar outras vias de análise. As explicações mais funcionalistas poderiam cair na tese do desaparecimento da religião, visto que a função poderia ser substituída por outras instâncias sociais, como a sociedade civil, os grandes eventos esportivos, o mercado ou as ideologias políticas. A nosso ver, essa postura também não 
ajudaria a compreender a persistência e a transformação da religião. É necessário enfatizar novamente que a tese que estamos desenvolvendo aqui aponta para a permanência da religião, nas mais diferentes formas, sem necessariamente cair numa visão ontológica.

As mudanças sociais não poderiam deixar de colocar suas marcas nas vivências religiosas, uma vez que são culturalmente construídas e guardam os atributos históricos dos contextos sociais. Um sinal evidente dessa sociedade moderna é o da subjetivação, que marca a sociedade como um todo nas mais diferentes instâncias. Heelas e Woodhead (2005) defendem que o Ocidente passa por uma grande transformação. Para eles, a subjetivação da vida é sentida em amplos setores sociais. Trata-se de uma mudança de uma vida vivida de acordo com as expectativas e autoridades exteriores, para uma vida vivida de acordo com as experiências interiores. A subjetividade individual começa a ser a fonte última de significado e autoridade. O que passa a importar, mais do que as exigências da sociedade, é a realização do próprio sujeito. Isso pode ser percebido em diversos setores da vida social, como no casamento, na educação, na saúde e, como não poderia deixar de ser, também na religião. Para Heelas e Woodhead (2005, p. 131132), há uma verdadeira revolução espiritual em curso que aponta para uma vivência subjetiva da religiosidade. Se no momento anterior, as referências do indivíduo estavam voltadas às instituições externas, como uma religião tradicional, agora se voltam para questões internas, subjetivas, como consciência interior, experiências corporais, relação corpo-mente-espírito, entre outras.

De acordo com a conceituação de Hanegraaff, a Nova Era pode ser compreendida como um conjunto de espiritualidades seculares (1999b). Em consonância com a tese da subjetivação, é preciso entender como que práticas individuais, de acordo com a definição de Hanegraaff, podem marcar uma época social. Se a Nova Era é a religião do self, o que estaria garantindo a interlocução entre as diferentes manifestações a ponto de podermos categorizá-las como componentes de um mesmo fenômeno? Em outras palavras, se todas as novas 
espiritualidades fossem simplesmente manipulações individuais, não poderíamos compreendê-las como práticas distintas que comportam elementos em comum. Mas é esse caldo cultural, ou cultic milieu, ou ainda milieu holístico, que garante certa unidade e contribui para formar um conjunto mais amplo de práticas religiosas semelhantes. É bom ressaltar que muitos dos frequentadores dessas diferentes agências transitam entre elas e acabam formando redes de sociabilidade e de trocas simbólicas (AMARAL, 2000). A própria ênfase na centralidade do indivíduo faz com que ele não se sinta comprometido com nenhum tipo de instituição e frequente livremente os mais diferentes serviços.

Essa unidade do meio pode ser encontrada no conjunto de elementos que compõe o conteúdo simbólico e mitológico das novas espiritualidades. O que pode ser verificado com a análise dos discursos dos casos escolhidos como exemplos.

Um possível mito central desse meio traz a concepção de que a realidade é criada por cada um de nós. Esse indivíduo participa de um processo de evolução através de incontáveis existências, nesta ou em outras dimensões. É por meio do esforço interior que o self se livra das amarras que o prendem a uma existência limitada e abre os caminhos para a plenitude. Essa evolução não é apenas espiritual, mas integra o corpo, a mente e o espírito. Essas espiritualidades não querem ser reconhecidas como religião justamente pelo fato de que não querem se identificar como instituições regradas e centralizadas. Além do mais, as religiões são identificadas como estruturas que impedem o próprio crescimento do self. É interessante notar que muitos evitam falar da presença de lideranças, pois isso poderia ser identificado com algum tipo de estrutura hierarquizada. Preferem utilizar o termo "facilitador", que são aquelas pessoas que já atravessaram alguns "portais", termo corriqueiro no meio, e que podem dar algum tipo de conselho ou indicação. Mas é, fundamentalmente, o indivíduo que terá de traçar, por seus próprios meios, o seu caminho interior. Na Pró-Vida é propagada a ideia de que pessoas interessadas em despertar o potencial de suas capacidades mentais, psíquicas e espirituais encontrarão os meios para alcançar os fins desejados. 
Em vários dos casos levantados aparece a ênfase na transformação do indivíduo como um todo. Vimos que em alguns discursos a ideia da centelha divina no interior de cada um é enfatizada. "Você é Deus e o divino habita seu interior" parece ser um discurso recorrente e coerente com aquele mito fundador. A Escola de Iluminação Ramtha fala explicitamente que "cada um é responsável pela conquista de si mesmo" e o divino se encontra dentro de cada um de nós. Cada indivíduo é o seu próprio mestre, mas pode se espelhar nos exemplos das pessoas que já atingiram os graus mais elevados. O espírito de Ramtha, manifestado através da canalização de JZ Knight, é um bom exemplo.

Forte e marcante, e também diretamente relacionado ao mito, é o discurso da cura pelo amor, veiculado explicitamente no Espaço Arthuriannno. Dizem que de nada adianta um amor falso, mas o verdadeiro amor é "aquele que está dentro de você”. Assim como esse, há vários outros espaços que oferecem serviços de cura e de conhecimento interior. Partindo do princípio que a evolução deve envolver mente, corpo e espírito, as práticas desses empreendimentos procuram dar conta de todas essas dimensões. Não é sem propósito que em seu discurso aparecem expressões como: "o bem estar integral do sujeito"; "unificação do corpo e mente"; "busca de prazer e bem estar através do equilíbrio entre corpo, mente e emoções".

Se esses conteúdos aparecem de forma mais sistematizada em centros que oferecem cursos, como a Pró-Vida, ou que proporcionam serviços de cura e autoconhecimento, como o Espaço Arthurianno, é na ioga que podemos encontrar todos eles de forma difusa. Isso demonstra o poder desse sistema simbólico no caldo cultural da Nova Era. Nos ensinamentos de ioga aqui selecionados, encontramos as ideias de que o desenvolvimento mental pode auxiliar o indivíduo na busca de um lugar interior e no alcance da imortalidade. Por meio da prática da meditação, o indivíduo pode experimentar o divino. Não um divino personalizado, mas que pode ser aquela centelha interior que deve ser acesa para alcançar os graus mais altos da evolução. 
Outros mitos também estão presentes no meio. De certa maneira estão em consonância ao mito da evolução do self, mas ajudam a compor o imaginário das pessoas que dele participam. O mito da lei da atração é bastante forte e combina com a concepção de pensamento positivo. Os acontecimentos, os infortúnios, assim como as doenças e as curas, podem ser compreendidos no interior de uma lógica mais ampla em que o indivíduo é responsável, pois está de acordo com mito fundante, e principalmente conecta esse sujeito ao cosmos, ao sentido maior. Essa lei da atração é maior do que ele, é cósmica e, dessa força ou energia (como costumam chamar), todos podem participar holisticamente.

A ideia de energia e força cósmica remete a outro mito central no universo nova era. Trata-se da mitologia da ciência. Não se fala de uma ciência comprovada e compartilhada academicamente, mas de uma nova ciência, ou Nova Aliança, como chamou o químico, e premio Nobel, Ilya Prigogine (1997). É uma ciência que irá, ainda, promover a evolução humana, trazendo conhecimentos ainda não alcançados pela ciência atual, vista como limitada. De certa maneira, esse apelo à autoridade da ciência satisfaz o imaginário das pessoas da nossa sociedade, que foram ensinadas a pensar na ciência como detentora da verdade.

Nessa mitologia da ciência podemos localizar duas fontes centrais. Por um lado aparecem vários elementos que guardam relação com a física das partículas subatômicas. O universo da física quântica, mesmo que incompreendido, é utilizado como uma espécie de comprovação de outras dimensões, inclusive espiritual. As categorias energia e vibração, principalmente quando adjetivadas com a dimensão cósmica, estão relacionadas à concepção dessa nova ciência. A física quântica deixa de ter seus significados originais, do próprio meio científico, e ganha uma conotação outra, metaempírica. Mesa quântica, cura quântica, terapia quântica são apenas alguns exemplos do uso dessa categoria. O outro tipo de recorrência à ciência aparece relacionada à psicologia e às ciências da mente. Crêse que a consciência pode se expandir e atingir outros níveis além dessa dimensão. Acredita-se que podemos conhecer tudo aquilo que ainda está desconhecido. $\mathrm{O}$ termo espiritual é, muitas vezes, utilizado como uma busca de evolução mental 
relacionada com energia e expansão da consciência, como é o caso apontado da ioga. A consciência e energia da mente são encaradas como maneira de alcançar a iluminação.

\section{Conclusões}

Feitas essas explanações do conteúdo simbólico do meio nova era e indicadas as transformações históricas que possibilitaram o surgimento da subjetivação e o consequente mito de que o indivíduo é o seu próprio criador e seu próprio Deus, é preciso compreender melhor onde está o religioso nessas novas espiritualidades. Se a Nova Era articula elementos seculares, onde estaria aquilo que garantiria uma aura de religiosidade? O que a torna religião?

De acordo com Hanegraaff, mesmo articulando elementos retirados do meio secular, essas novas espiritualidades seriam religião na medida em que estabelecem relação entre o mundo cotidiano e quadro metaempírico de significados. Longe de quaisquer comprovações científicas, os elementos seculares usados estão longe de seus ambientes originais. Ganharam uma aura metaempírica, remetem a universos não presentes e realidades para além de qualquer uma que possa ser comprovada empiricamente. A crença em um processo de elevação espiritual ilimitado por meio do qual o indivíduo aprende com suas experiências não está ao alcance de nenhum teste científico. $\mathrm{O}$ mito de que cada um de nós traz dentro de si a potência cósmica maior e que a divindade se encontra em todas as coisas e no interior dos indivíduos não deixa de ser propriamente um mito, uma narrativa sagrada que remete o indivíduo a outras dimensões da existência. A presença de seres iluminados, ou de outras civilizações, representa a figura do herói mítico, aquela figura exemplar que participa de uma grande aventura, com iniciação, desafios e conquistas. No fundo uma metáfora com simbologias atuais do que ocorre com os indivíduos da sociedade contemporânea. 
O que talvez ainda falte na explicação de religião de Hanegraaff é justamente aquilo que permitiria a compreensão do porquê da persistência da religião. A religião se transformou, encontrou adaptações e realizou reconfigurações para permanecer na sociedade atual. Não como uma instituição secular que substitui as funções ora exercidas pela religião, mas como novas formas religiosas, como as espiritualidades da Nova Era. Falamos anteriormente que a definição de Hanegraaff, assim como a de Geertz, permitiria a compreensão de uma singularidade da religião sem necessariamente cair em visões substantivistas ou ontológicas. Nas definições desses dois autores há uma recorrência à ideia de que os símbolos possuem um poder em si que promove a ligação entre um mundo cotidiano e um mundo imaginado ou metaempírico. Esse sistema simbólico se modifica a cada contexto social e as espiritualidades atuais, como as demonstradas aqui, são coerentes a uma boa parcela da vida social contemporânea. Essas espiritualidades são, portanto, religião. Mas permanece a pergunta, de onde vem esse poder dos símbolos e por que a religião é persistente?

Podemos compreender que todas essas concepções guardam um viés idealista. Os sistemas simbólicos, conjuntos de crenças e ideias, teriam a força de estabelecer a ligação que garantiria o elemento religioso. Esses sistemas podem até ser constituídos por elementos seculares, mas, sendo coletivos, garantiriam o elemento religioso.

Fica, então, uma questão ainda a ser respondida. Sem lançar mão de explicações de ordem metafísica ou idealista, como compreender a presença do religioso nas diferentes manifestações religiosas e nas espiritualidades? É possível que a natureza da religião possa ser compreendida a partir da própria natureza humana. Uma natureza que insiste em criar seres com capacidades que vão além daquelas que os simples mortais são capazes e em acreditar que todos nós podemos, de alguma maneira, participar de uma vida mais ampla, que não se esgota na finitude da morte. Por ora, podemos dizer que a religião vai muito além. 


\section{REFERÊNCIAS}

AMARAL, Leila. Carnaval da alma. Comunidade, essência e sincretismo na Nova Era. Petrópolis: Vozes, 2000.

BARKER, Eileen. New religious movements: a practical introduction. London: MSO, 1989.

BEYER, Peter. Conceptions of religion: on distinguishing scientific, theological, and "official” meanings. Social Compass, Louvain, v. 50, n. 2, p. 141-160, 2003.

BITTENCOURT Filho, José. Matriz religiosa brasileira. Religiosidade e mudança social. Petrópolis: Vozes/Koinonia, 2003.

BORG, Meerten B. What is religion? In: PLATVOET, J. and MOLENDIJK, A. The pragmatics of defining religion. Contexts, concepts and contests. Leiden; Boston, Köln: Brill, 1999. p. 397- 408.

BOYER, Pascal. Religion explained. The evolutionary origins of religious thought. New York: Basic Books, 2001.

CAMPBELL, Colin. A ética romântica e o espírito do consumismo modero. Rio de Janeiro: Rocco, 2001.

CHARURI, Celso. Como vai a sua mente? Disponível em:

<http://pt.wikiquote.org/wiki/Celso_Charuri>. Acesso em: 11 jun. 2014.

CRUZ, Eduardo. Irreligião? Ou mutações religiosas conduzidas pela ciência? I

SIMPÓSIO REGIONAL DA ABHR-NE, Campina Grande, 2013. Disponível em:

<https://docs.google.com/file/d/oB324umQo-vnyOXdwVGowVmFKWUU/edit?pli=1>. Acesso em: 11 jun. 2014.

DROGERS, André. A religiosidade mínima brasileira. Religião e Sociedade, São Paulo, v. 14, n.2, p. 62-86, 1987.

ESCOLA DE ILUMINAÇÃO DE RAMTHA. Introdução. Disponível em: <http://www.vivermais.net/lb_intro.html>. Acesso em: 22 maio 2014 b.

ESCOLA DE ILUMINAÇÃO DE RAMTHA. Quem é Ramtha? Disponível em: <http://www.vivermais.net/quem_ramtha.html>. Acesso em: 22 maio 2014a.

ESPAÇO ARTHURIANNO. Espaço Arthurianno. Disponível em: <http://www.espacoarthurianno.com.br >. Acesso em: 30 maio $2014 \mathrm{a}$.

ESPAÇO ARTHURIANNO. Mesa Quântica Arcturiana. Disponível em: <http://www.espacoarthurianno.com.br/tratamentos/consulta-na-mesa-quantionica>. Acesso em: 30 maio 2014b. 
GEERTZ, Clifford. A religião como sistema cultural. In: GEERTZ, Clifford. A interpretação das culturas. Rio de Janeiro: Zahar ed., 1978. p. 65-92.

GUERRIERO, Silas. Os Novos Movimentos Religiosos. O quadro brasileiro. São Paulo: Paulinas, 2006.

HANEGRAAFF, Woulter. Defining religion in spite of history. In.: MOLENDIJK, A. \& PLATVOET, Jan. The pragmatics of defining religion. Contexts, concepts \& Contests. Leiden; Boston; Köln: Brill, 1999a. p. 337-378.

HANEGRAAFF, Woulter. New Age religion and western culture. Esoterism in the mirror of secular thought. New York: Brill, 1996.

HANEGRAAFF, Wouter. New Age spiritualities as secular religion: a historian's perspective. Social Compass, Louvain, v. 2, n. 46, p. 145-16o, 1999 b.

HEELAS, Paul. The New Age Movement. Oxford: Blackwell Publ., 1997.

HEELAS, Paul; WOODHEAD, Linda. The spiritual revolution. Why religion is giving way to spirituality. London: Blackwell Publishing, 2005.

HOCK, Klaus. Introdução à ciência da religião. São Paulo: Loyola, 2010.

KOZASA, Elisa Harumi. A prática de meditação aplicada ao contexto da saúde. Saúde Coletiva, São Paulo, v. 10, n. 3, p. 63-66, 2006.

MAGNANI, José Guilherme. A mystica urbe. Um estudo antropológico sobre o circuito neoesotérico na metrópole. São Paulo: Studio Nobel, 1999.

MENEZES, Carolina B.; DELL'AGLIO, Débora D. Os efeitos da meditação à luz da investigação científica em Psicologia: revisão de literatura. Psicologia: ciência e profissão, Brasília , v. 29, n. 2, jun. 2009. Disponível em:

<http://pepsic.bvsalud.org/scielo.php?script=sci_arttext\&pid=S1414-

98932009000200006\&lng=pt\&nrm=iso >. Acesso em: 11 jun. 2014.

NEGRÃO, Lísias Nogueira (Org.). Novas tramas do sagrado. Trajetórias e multiplicidades. São Paulo: Edusp, Fapesp, 2009.

PADEN, Willian. Interpretando o sagrado. Modos de conceber a religião. São Paulo: Paulinas, 2001.

PASSOS, João D.; USARSKI, Frank (Org.). Compêndio de Ciência da Religião. São Paulo: Ed. Paulinas; Paulus, 2013.

PRIGOGINE, Ilya; STENGERS, Isabelle. A nova aliança. Brasília: UnB, 1997.

PRÓ-VIDA. A Pró-Vida. Integração cósmica. Disponível em:

<http://www1.provida.org.br/pt_BR/page/provida >. Acesso em: 02 jun. 2014a. 
PRÓ-VIDA. Carta de princípios. Disponível em:

<http://www1.provida.org.br/pt_BR/page/statement-of-principles $>$. Acesso em: 02 jun. $2014 \mathrm{~b}$.

RÁDIO MUNDIAL. A meditação andando e o yoga. Disponível em:

<http://radiomundial.com.br/assuntosabordados/?id=376>. Acesso em: 11 jun. 2014b.

RÁDIO MUNDIAL. Otávio Augusto Leal. Disponível em:

<http://radiomundial.com.br/comunicadores/?id=47>. Acesso em: 11 jun. 2014a.

RÁDIO MUNDIAL. Programação. Disponível em:

<http://radiomundial.com.br/programacao >. Acesso em: 30 maio 2014c.

SALER, Benson. Conceptualizing religion: some recent reflections. Religion, [s.l.], 38, n. 3, p. 219-225, 2008. Disponível em:

<http://www.sciencedirect.com/science/article/pii/So048721Xo8000389>. Acesso em: 22 set. 2012.

SCHILBRACK, Kevin. Religions: are there any? Journal of the American Academy of Religion, Oxford, v. 78, n. 4, p. 112-1138, 2010.

SIEGEL, Pamela. Yoga e saúde: o desafio da introdução de uma prática nãoconvencional no SUS. 2010. 206 f. Tese (Doutorado) - Unicamp, Faculdade de Ciências Médicas, Campinas.

TERRIN, Aldo Natale. O sagrado off limits. A experiência religiosa e suas expressões. São Paulo: Loyola, 1998.

WILSON, Bryan; CRESSWELL, Jamie (Ed.). New religious movements. Challenge and response. London: Routledge, 1999.

WILSON, Bryan. Sociologia de las sectas religiosas. Madrid: Guadarrama, 1970. 